\title{
ВMJ Global Health Patient-centric research in the time of COVID-19: conducting ethical COVID-19 research in Africa
}

\author{
Victoria Nembaware, ${ }^{1}$ Nchangwi Syntia Munung, ${ }^{1}$ Alice Matimba, ${ }^{2}$ Nicki Tiffin ${ }^{3,4}$
}

To cite: Nembaware $\mathrm{V}$, Munung NS, Matimba A, et al. Patient-centric research in the time of COVID-19: conducting ethical COVID-19 research in Africa. BMJ Global Health 2020;5:e003035. doi:10.1136/ bmjgh-2020-003035

Handling editor Seye Abimbola

- Additional material is published online only. To view please visit the journal online (http://dx.doi.org/10.1136/ bmjgh-2020-003035).

Received 29 May 2020 Revised 19 June 2020 Accepted 22 June 2020

Check for updates

(C) Author(s) (or their employer(s)) 2020. Re-use permitted under CC BY-NC. No commercial re-use. See rights and permissions. Published by BMJ.

${ }^{1}$ Human Genetics Division, University of Cape Town, Cape Town, South Africa

${ }^{2}$ Advanced Courses and Scientific Conferences, Wellcome Genome Campus, Cambridge, UK

${ }^{3}$ Wellcome Centre for Infectious Disease Research in Africa, University of Cape Town, Cape Town, South Africa

${ }^{4}$ Computational Biology Division, University of Cape Town, Cape Town, South Africa

Correspondence to Professor Nicki Tiffin; nicki.tiffin@uct.ac.za

\section{INTRODUCTION}

Without effective management, COVID-19 could be catastrophic in Africa, exacerbated by high infectious and non-infectious disease burdens, poor healthcare access and limited health resources. ${ }^{1}$ Projections estimate over 110 million infections and 300000 mortalities in sub-Saharan Africa alone. ${ }^{2}$ Global evidence identifies contributing risk factors such as age, gender and existing comorbidities, but drivers of disease severity and poor survival in some patients are still unclear. ${ }^{3}$ African genetic variation underlies many differences in pathogen susceptibility, disease severity, drug response and patient outcomes compared with rest-of-world populations. ${ }^{45}$ African COVID-19 disease profiles may also differ given unique regional environmental challenges, population structure and genetic make-up, and potential proliferation of specific virus strains, limiting transferability of research findings from other continents.

An urgent pandemic response is driving rapid assembly of COVID-19 research programmes, accelerated ethics review by Institutional Review Boards (IRBs), and substantial funding disbursementfor example, $€ 4$ million: European and Developing Countries Clinical Trials Partnership, €2.26million: Wellcome Trust, US\$100 million for Africa and South Asia, Bill and Melinda Gates Foundation, 42 million ZAR: South African government, and other funds collated by the African Academy of Sciences (https://www.aasciences.africa/ covid-19-updates).

History suggests that times of crisis in Africa are often exploited for unethical collection and use of samples and data, and African research participants can become targets of ethics dumping-where researchers conduct studies ethically unacceptable in their home countries in a low-regulation environment. ${ }^{67}$ Unethical data/biospecimen
Summary box

Research practices should be ethical and transparent, prioritising patient benefits and provision of health carehealthcare, and respecting participant autonomy.Priority should be given to research studies with the potential for immediate translated patient benefits based on realistic interventions appropriate to an African context.

- Institutional Ethics Review Boards should be supported to ensure high-quality, rapid review of research proposals. Informed consent models should reflect research risk level and the heightened vulnerability of the study population during a health crisis. Consideration should be made for patients who are too ill to give consent, and inclusion of data from deceased patients. Participant information must be accessible and relevant to participants, in local languages, and include clear, realistic descriptions of potential benefits and risks.

- Community engagement using appropriate media channels can be effective in providing information and counter dissemination of false information.

- Funders and journal editors can provide additional checks and balances to ensure funded and published research from Africa is ethical, patient-centric, relevant and transparent.

collection practices also occurred under cover of humanitarian aid, for example, during the West African Ebola crisis $^{8}$ : Ebola data remain off-Continent in the Infectious Diseases Data Observatory in the UK, ${ }^{9}$ and African-authored research using data from the Ebola crisis is hard to find..$^{10}$

Understanding COVID-19 in African patients through research is urgently needed for effective healthcare tailored to African context and needs. Furthermore, African participation in COVID-19 research contributes complex and diverse genetics together with environmental exposures to different infectious agents, biospheres and noncommunicable diseases to global COVID-19 knowledge. Biomedical research can improve 
Box 1 Types of consent and ways to request consent from participants

(definitions obtained from the Sickle Cell Disease Ontology ${ }^{16}$ )

Types of consent used in emergencies

Prospective informed consent: Voluntary authorisation, by a patient or research participant, with full comprehension of the risks involved, for diagnostic or investigative procedures and for medical and surgical treatment.

Waived consent: Consent is obtained at a population level through public/community is engagement where individual consenting is not feasible. This is normally done for low risk studies and/or in case of emergencies.

Deferred consent: Consent is taken later after enrolment into study especially in emergency situations.

Proxy consent: A legal representation or family member of the participant gives consent on the participant's behalf.

\section{Ways of recording consent}

Written consent: Patient or representative signs a document as a way of giving consent.

Verbal consent: A witness should be present when verbal consent is given. Verbal consent could also be recorded.

COVID-19 diagnosis, prognosis and therapeutics to combat the pandemic in Africa and globally, and inform approaches to possible future pandemics; but participation should not come at a personal cost to participants or at the expense of patient-centric, ethical research. All stakeholders need to actively safe-guard against unethical research being conducted in Africa, accordingly.

We propose two central tenets for patient-centric ethical COVID-19 research involving participants in Africa: that research practices are ethical and transparent, prioritising patient benefits and provision of healthcare; and that participant autonomy and engagement are upheld. We discuss approaches to ensure the urgency of the pandemic does not provide cover for unethical research.

\section{ETHICAL, TRANSPARENT, PATIENT-CENTRIC RESEARCH Ethical review of research}

Nationally recognised IRBs have a key role in ensuring ethical research conduct in times of crisis. In this novel COVID-19 pandemic, IRBs have no recourse to historical evidence, and require support in both decision-making challenges and a greatly increased workload. Previous pandemic experience has informed recommendations for strengthening and expediting IRB processes, ${ }^{11}{ }^{12}$ members of the scientific community can be co-opted to assess proposals for scientific integrity, and government offices and scientific organisations can provide guidelines for acceptable practices (eg, African Academy of Sciences COVID-19 research ethics, https://www. aasciences.africa/).

\section{Managing resources and research priorities}

Maximising benefit to patient populations is essential for ethical COVID-19 research in Africa, given limited healthcare capacity. With increased demands for clinical care, study design should not divert scarce healthcare resources from patient care, and must ensure minimal impact on healthcare professionals who may already face ethical challenges in providing healthcare. ${ }^{13}$ Where possible, research should use residues of samples collected during standard healthcare. Priority should be given to immediate-returns research and collaborative programmes that maximise output-per-spend, share data and publish interim results under responsible governance and informed consent structures. Translational research should investigate affordable interventions that might be realistically effected within Africa. Rapid dissemination of confirmed findings can maximise patient benefits, while exploratory research without immediate translation can take lower priority until the crisis is contained. Sample and data collection, storage and access must be properly managed within Africa to ensure specimens and data are not expatriated without appropriate consent and permissions, with oversight to ensure ethical and equitable access going forward.

\section{Managing conflicts of interest}

Expedited funding, review, support and publication of COVID-19 research requires concomitant checks and balances to ensure valid findings despite rapid processing. Researchers face pressure to access funding and generate results and high-impact publications rapidly, which can present conflicts of interest around patient-oriented versus career-driven research priorities-even leading to researchers side-stepping informed consent processes and prioritising 'scoop' papers rather than solid clinical and epidemiological output. Peer reviewers must be meticulous in reviewing COVID-19-related research, and journal editors can incorporate additional oversight for ethical compliance and scientific validity of rapid-review manuscripts-especially where non-African authors analyse African data and samples.

\section{RESPECT FOR PATIENT AUTONOMY AND ENGAGEMENT}

African patients must be recognised as primary stakeholders in COVID-19 research, through appropriate engagement, information and consent processes.

\section{Community engagement}

Anxiety, social disruption and ill health of potential participants during the pandemic demand extensive community engagement even though face-to-face engagement may be unfeasible. Effective, uncomplicated communication can address distrust in research in Africa, ${ }^{12}$ and clearly differentiate research participation from routine healthcare. Non-traditional engagement of community members provided in local languages by local fieldworkers must accommodate potentially limited resources available to participants and researchers, for example, 


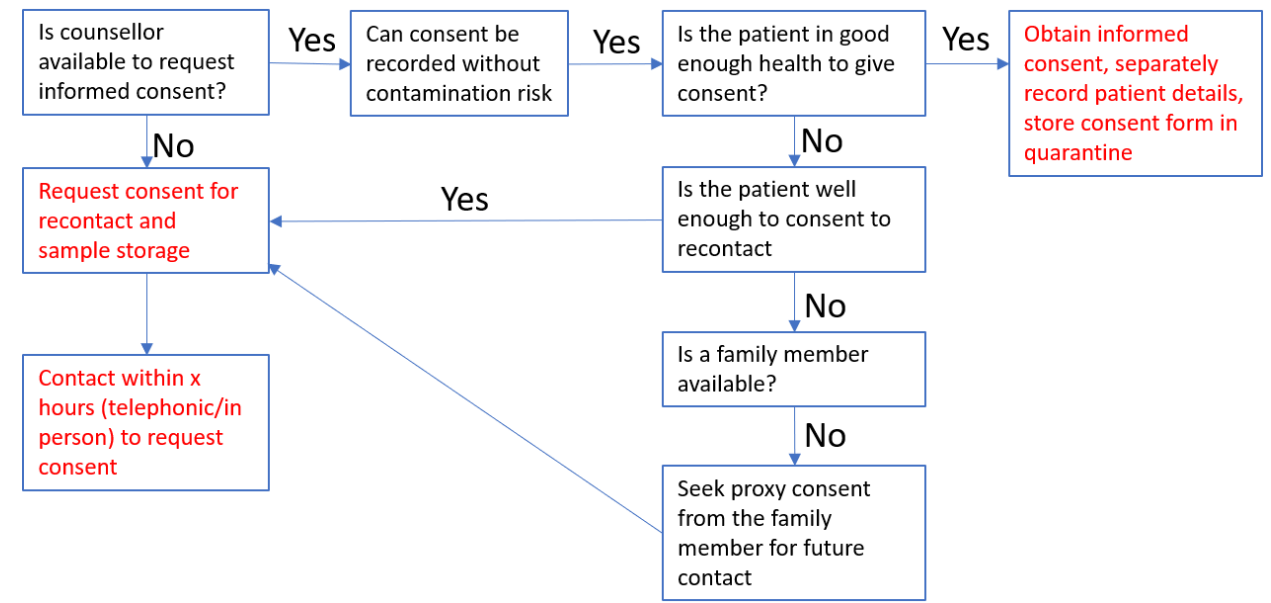

Figure 1 Example work flow for informed consent for a COVID-19 study. This example allows for (1) where a patient is ill or a counsellor is not available, a request for permission to re-contact a patient in the future about the study, and to temporarily store samples without using them. Recontact consent might also be obtained from a family member as a proxy consent; (2) request for participation in the study with full consent.

using call-back short message services (SMS), toll-free numbers for information, printed materials and free-data websites combining information about COVID-19 public health measures and proposed studies. Leveraging broadcast media (television and radio), social media channels can engage communities and also counter dissemination of false information. Enrolled participants might access information using WhatsApp Q\&A chatlines, and receive data and call-time vouchers to communicate directly with trained counsellors. Feedback of research findings by posters, digital content (SMS), broadcast and social media channels and through community leaders also respects community members as primary stakeholders, and ongoing assessment of the impact of findings can identify and address stigmatisation as it arises.

\section{Participant information}

Participant information must be accessible, relevant and sufficient to understand proposed research, provided in local languages (generic example in English for biomedical research, online supplementary file 1). Clear, realistic descriptions of potential benefits, or lack thereof, as well as participation risks are required. IRB oversight can ensure access to limited healthcare resources is not used to coerce participation in studies and consideration of potential social risks such as stigmatisation which are not yet understood as the pandemic unfolds in Africa. Locally relevant COVID-19 health promotion information and links to local psycho-social support should also be provided.

\section{Respecting patient autonomy through informed consent}

Different research consent models need to reflect research risk level (box 1) and the heightened vulnerability of the study population during a health crisis. IRBs can provide practical guidance regarding participant information and informed consent templates (examples provided in supplementary data). Consideration must be

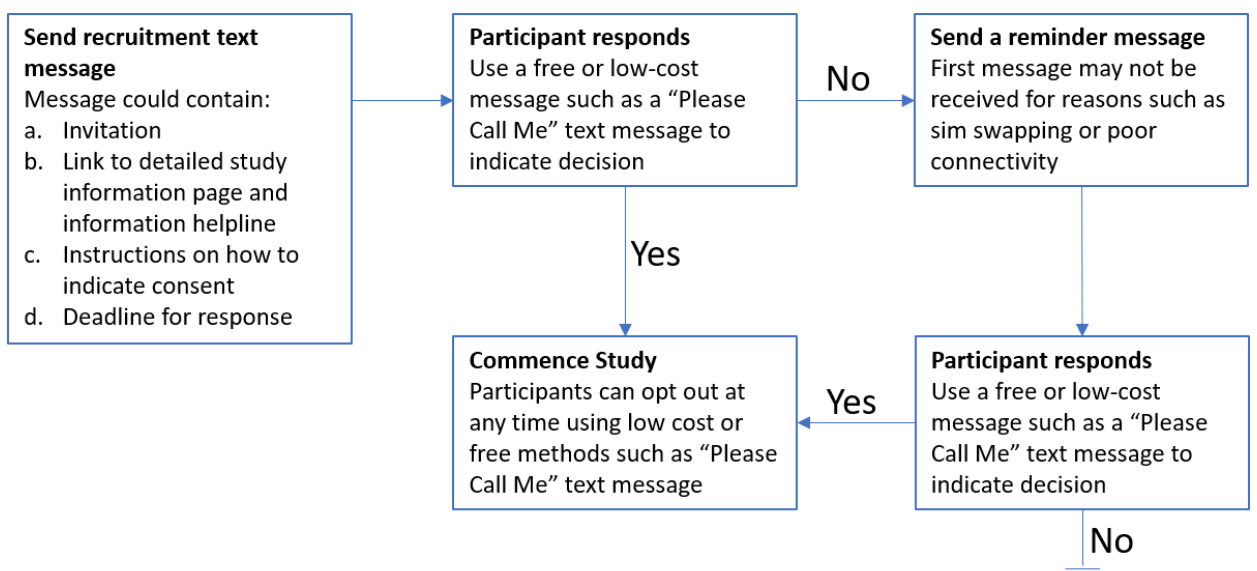

Figure 2 Contacting individuals in an existing study to request participation in a new study. Individuals in an existing study can be approached with an invitation to join further studies using locally-appropriate communications. this may be a text message (short message services) in areas where smart phones are not in current use. Call back facilities, such as 'please call me' text messages are often available where data and call time is limited by socioeconomic constraints. 
given for patients too ill to give informed consent, and we provide an example for this scenario using preliminary consent from patient or family member to store samples collected as part of routine care and recontact participants (online supplementary file 2), and to subsequently invite study participation and full informed consent on recovery (figure 1, online supplementary file 3). Proxy consents, and assent by minors, however, require careful oversight by IRBs to prevent exploitation of alreadyvulnerable groups made more so by pressures of the pandemic. Given the importance of understanding what drives disease severity, it is essential to include deceased patients in research: where possible proxy consent may be requested from their family members, otherwise a waiver of consent might be requested from IRBs for inclusion of their data and samples in ongoing studies. ${ }^{14}$

\section{Informed consent considerations for researchers}

Informed consent processes must protect researchers from infection: participant data can be recorded separately to signed forms; and physical distance, screens or online consultation can protect counsellors and data collectors. Where digitalisation is not possible, signed forms can be sealed in bags and stored for a quarantine period; or verbal consent can be digitally recorded. Existing datasets may be retrospectively analysed, or used as control data for COVID-19 studies where ethics approval is in place. Such data can be anonymised, de-identified, perturbed and aggregated to be useful comparison datasets without compromising participants; or new consent can be sought for repurposing existing data. We present an example recruitment strategy adapted from a minimal risk HIV study where participants were approached for new consents through mobile text messaging from an existing HIV media campaign registry (figure 2 ). ${ }^{15}$

\section{CONCLUSION}

Emergency and pandemic conditions do not necessitate cutting ethical corners or undermining participant autonomy to conduct essential research in Africa; which must instead be patient-centric, given that patients may already be compromised by limited access to healthcare, a high burden of comorbidities and socioeconomic insecurity. Multiple avenues of support can ensure high quality, ethical research by protecting stretched clinical care resources, prioritising patient recovery and maximising patient benefits while upholding patients' right to make informed choices about participation wherever possible. Research ethics during pandemics are necessarily complex, but ongoing learnings should continue to be carried forward to inform future responses. ${ }^{11} 12$

Contributors NT conceived of the study and prepared the first draft. VN, AM and NSM contributed ideas and text to the first and subsequent iterations of the manuscript, and were involved in the writing process thereafter.
Funding NT receives funding from the CIDRI-Africa Wellcome Trust grant (203135/Z/16/Z), the NIH H3ABioNET award (U24HG006941) and the NIH B-Positive Grant (R01HD080465). VN and NSM receive funding from NHLBI (U24HL135600).

Competing interests None declared.

Patient consent for publication Not required.

Provenance and peer review Not commissioned; externally peer reviewed.

Data availability statement № additional data are available.

Open access This is an open access article distributed in accordance with the Creative Commons Attribution Non Commercial (CC BY-NC 4.0) license, which permits others to distribute, remix, adapt, build upon this work non-commercially, and license their derivative works on different terms, provided the original work is properly cited, appropriate credit is given, any changes made indicated, and the use is non-commercial. See: http://creativecommons.org/licenses/by-nc/4.0/.

ORCID iD

Nicki Tiffin http://orcid.org/0000-0001-5083-2735

\section{REFERENCES}

1 Economic Commission for Africa. COVID-19 in Africa: protecting lives and economies. Addis Ababa, Ethiopia, 2020. Available: https:// www.uneca.org/sites/default/files/PublicationFiles/eca_covid_ report_en_24apr_web1.pdf [Accessed 4 May 2020]

2 Walker P, Whittaker C, Watson O, et al. Report 12: the global impact of COVID-19 and strategies for mitigation and suppression. Imperial College London 2020.

3 Zheng Z, Peng F, Xu B, et al. Risk factors of critical \& mortal COVID-19 cases: A systematic literature review and meta-analysis. Journal of Infection 2020:S0163445320302346.

4 Naidoo A, Chirehwa M, Ramsuran V, et al. Effects of genetic variability on rifampicin and isoniazid pharmacokinetics in South African patients with recurrent tuberculosis. Pharmacogenomics 2019;20:225-40.

5 Meriki HD, Tufon KA, Anong DN, et al. Genetic diversity and antiretroviral resistance-associated mutation profile of treated and naive HIV-1 infected patients from the northwest and Southwest regions of Cameroon. PLoS One 2019;14:e0225575.

6 Schroeder D, Cook J, Hirsch F, et al. Ethics dumping: case studies from north-south research collaborations. Springer International Publishing, 2017.

7 Goussanou W. COVID-19 trials at risk after Africa 'racism' backlash. Sci Dev Net 2020.

8 Freudenthal E. Ebola's lost blood: row over samples flown out of Africa as 'big pharma' set to cash in. The Telegraph, 2019. Available: https://www.telegraph.co.uk/news/0/ebolas-lost-bloodrow-samples-flown-africa-big-pharma-set-cash/ [Accessed $10 \mathrm{Feb}$ 2019].

9 Conton B. Build the Ebola database in Africa. Nature 2017:551:143-4.

10 Hagel C, Weidemann F, Gauch S, et al. Analysing published global Ebola virus disease research using social network analysis. PLoS Negl Trop Dis 2017;11:e0005747.

11 Saxena A, Horby P, Amuasi J, et al. Ethics preparedness: facilitating ethics review during outbreaks - recommendations from an expert panel. BMC Med Ethics 2019;20:29.

12 Folayan MO, Peterson K, Kombe F. Ethics, emergencies and Ebola clinical trials: the role of governments and communities in offshored research. Pan Afr Med J 2015;22 Suppl 1:10.

13 Yakubu A, Folayan MO, Sani-Gwarzo N, et al. The Ebola outbreak in Western Africa: ethical obligations for care. J Med Ethics 2016;42:209-10.

14 Moodley K, Allwood BW, Rossouw TM. Consent for critical care research after death from COVID-19: arguments for a waiver. South African Medical Journal 2020;110.

15 de Tolly K, Skinner D, Nembaware V, et al. Investigation into the use of short message services to expand uptake of human immunodeficiency virus testing, and whether content and dosage have impact. Telemed J E Health 2012;18:18-23.

16 Sickle Cell Disease Ontology Working Group. The sickle cell disease ontology: enabling universal sickle cell-based knowledge representation. Database 2019;2019. doi:10.1093/database/baz118. [Epub ahead of print: 01 Jan 2019]. 